\title{
Comparison of omeprazole and cimetidine in reflux oesophagitis: symptomatic, endoscopic, and histological evaluations
}

\author{
C M Bate, P W N Keeling, C O'Morain, S P Wilkinson, D N Foster, R A Mountford, \\ J M Temperley, R F Harvey, D G Thompson, M Davis, I C Forgacs, K S Bassett, \\ P D I Richardson
}

\begin{abstract}
Symptomatic patients with endoscopically verified reflux oesophagitis were randomised to a double blind trial in which they received either omeprazole ( $20 \mathrm{mg}$ once daily) or cimetidine (400 $\mathbf{~} \mathrm{g}$ four times daily) for four, and if necessary, eight weeks. In an intention to treat' analysis, oesophagitis was found to have healed after four weeks in 77 of $137(56 \%)$ in the omeprazole group and in 34 of $133(26 \%)$ in the cimetidine group $(\mathbf{p}<\mathbf{0} \cdot 001)$. By eight weeks these values were $71 \%$ and $35 \%$ respectively; $\mathbf{p}<\mathbf{0 . 0 0 1}$. Histological assessments were available for $73 \%$ of the patients. At entry, $63 \%(66$ of 104) in the omeprazole group and 60\% (56 of 94 ) in the cimetidine group (ns) had abnormal histology. After the study, the proportions of patients who initially had had abnormal histology but who then progressed to normal were 67\% (44 of 66: omeprazole) and 48\% (27 of 56: cimetidine) respectively $(p<0.001)$. All patients had reflux symptoms at entry. After four weeks, $46 \%$ in the omeprazole group and $22 \%(\mathrm{p}<0.001)$ in the cimetidine group were asymptomatic. Diary cards completed for the first two weeks showed that patients treated with omeprazole experienced fewer reflux symptoms by day and night and used fewer antacids. Omeprazole, $20 \mathrm{mg}$ once a day for four to eight weeks, healed a greater proportion of patients with reflux oesophagitis than cimetidine, $1.6 \mathrm{~g}$ per day, assessed endoscopically and histologically, and relieved more patients' symptoms.
\end{abstract}

J M Temperley

Frenchay Hospital, Bristol

R F Harvey

Hope Hospital, Salford D G Thompson

Royal United Hospital, Bath

M Davis

Dulwich Hospital,

London

I C Forgacs

Astra Pharmaceuticals Ltd, Kings Langley,

Hertfordshire

K S Bassett

P D I Richardson

Correspondence to:

Dr C M Bate, Royal Alber

Edward Infirmary, Wigan

Lane, Wigan, Lancashire

WN12NN.

Accepted for publication

1 December 1989
Figure 1: Healing of oesophagitis after four and eight weeks' treatment with omeprazole (20 mg om) or cimetidine (400 mg qds). Small bars show $95 \%$ confidence intervals.
Omeprazole (Losec, Astra), in doses of 20-60 mg once daily heals a greater proportion of reflux oesophagitis lesions than ranitidine $150 \mathrm{mg}$ twice daily within four to 12 weeks. ${ }^{1-4}$ In this study, we compared $20 \mathrm{mg}$ omeprazole once daily with the relatively high dose of $1.6 \mathrm{~g}$ cimetidine daily (400 mg four times a day) using endoscopic and histological assessments of the resolution of reflux oesophagitis coupled with symptoms elicited at clinic visits and recorded by the patients on diary cards. This combined approach in comparing healing and symptom relief with omeprazole and an $\mathrm{H}_{2}$ receptor antagonist has not been reported before and we believe that it represents a critical way of assessing the possible benefit of omeprazole compared with an established treatment.

\section{Methods}

TRIAL DESIGN

Patients aged 18 years and over were eligible if they had symptomatic oesophagitis of grade I-IV verified endoscopically within the week before randomisation to this trial. Exclusion criteria were: oesophageal stricture or varices; pregnancy or lactation; upper gastrointestinal surgery; oesophageal dilatation within eight weeks; use of antireflux drugs within one week; use of any investigational drug within four weeks; severe concomitant disease; use of anticoagulants, theophylline, or phenytoin; or previous randomisation in this trial.

The trial was a randomised, double blind (double dummy) comparison of two oral treatments - omeprazole, $20 \mathrm{mg}$ once a day, and cimetidine, $400 \mathrm{mg}$ four times a day - in 17 centres in the British Isles. Details of recruitment are given at the end of the paper. Compliance was assessed by tablet counts, inquiry by the physician, and by patients confirming that they had taken the tablets and capsules each day on the diary cards. Ethics committee approval was obtained at each centre, and patients gave written informed consent. The initial treatment period was four weeks but if symptoms remained after this period or oesophagitis was still present at endoscopy, treatment continued for a total of eight weeks.

CLINICAL ASSESSMENTS

Endoscopy. Oesophagogastroduodenoscopy was carried out at entry (up to seven days before to randomisation), after four weeks (25-33 days), 
TABLE I Patient characteristics at entry to the study

\begin{tabular}{lll}
\hline & $\begin{array}{l}\text { Omeprazole } \\
\text { group }\end{array}$ & $\begin{array}{l}\text { Cimetidine } \\
\text { group }\end{array}$ \\
\hline Total number (M:F) & $138(88: 50)$ & $134(82: 52)$ \\
Age (yrs), mean (SD) & $53(15)$ & $52(16)$ \\
Smokers (\%) & 20 & 29 \\
Alcohol consumers (\%) & 42 & 34 \\
Duration of reflux symptoms (\%) & & \\
$\quad \leqslant 2$ years & 57 & 58 \\
$2-5$ years & 22 & 22 \\
$>5$ years & 20 & 20 \\
Grade of oesophagitis (\% (no)) & & \\
1 & $12(16)$ & $13(18)$ \\
2 & $36(49)$ & $39(52)$ \\
3 & $50(69)$ & $42(56)$ \\
4 & $3(4)$ & $6(8)$ \\
Extent of oesophagitis (\% (no)) & & \\
$\quad 1-4 \mathrm{~cm}$ & $46(64)$ & $49(66)$ \\
$5-9 \mathrm{~cm}$ & $44(61)$ & $42(56)$ \\
$\geqslant 10 \mathrm{~cm}$ & $9 *(11)^{\star}$ & $9(12)$ \\
Barrett's oesophagus & $7(10)$ & $3(4)$ \\
\hline$\star 1$ missing & &
\end{tabular}

and where necessary after eight weeks (50-64 days). Grading was as follows:

Grade $0=$ Normal oesophageal mucosa;

Grade $1=$ Erythema and friability with spontaneous or contact bleeding;

Grade 2=Isolated round or linear erosions affecting the lower $2 \mathrm{~cm}$ of the oesophagus and not the entire circumference;

Grade $3=$ Erosions extending above $2 \mathrm{~cm}$ or affecting the entire circumference;

Grade 4=Frank benign ulcer;

Group 5= Stricture.

Patients with erosive or ulcerative oesophagitis of grade $1,2,3$, or 4 entered the study. Healing was defined as complete re-epithelialisation of the lesion - that is, grade 0 . The presence and extent of Barrett's oesophagus - that is columnar lined epithelium above the gastrooesophageal junction - was recorded.

Histology. Biopsy specimens were taken from the mucosa with oesophagitis before and at the end of treatment. Haemotoxylin and eosin stained sections were graded by one histopathologist (Dr Geraint Williams) who was blind to the treatment the patient received. The most severe of four specimens on each occasion were graded as follows:

Grade $0=$ Normal mucosa;

Grade $1=$ Minor abnormalities, either scanty intraepithelial polymorphs, or submucosal vascular dilatation, or basal epithelial cell thickening;

Grade 2=Conspicuous intraepithelial polymorphs;

TABLE II Percentage healing of reflux oesophagitis after four and eight weeks' omeprazole or cimetidine, by grade of severity assessed endoscopically at entry

\begin{tabular}{lll}
\hline & \multicolumn{2}{l}{$\%$ Healed } \\
\cline { 2 - 3 } Time, grade at entry & Omeprazole & Cimetidine \\
\hline Four weeks: & & \\
Grade 1 & 56 & 50 \\
Grade 2 & 63 & 31 \\
Grade 3 & 51 & 16 \\
Grade 4 & 50 & 0 \\
Eight weeks: & & \\
Grade 1 & 75 & 56 \\
Grade 2 & 76 & 48 \\
Grade 3 & 66 & 20 \\
Grade 4 & 75 & 0 \\
\hline
\end{tabular}

For proportions in each group at entry, see Table $I$.
Grade 3=Ulcer slough present

Symptoms at clinic visits. Patients were asked to grade their reflux symptoms both overall (none, mild, moderate, severe) and for specific symptoms (heartburn, regurgitation, dysphagia). They were asked to report any other symptoms and possible adverse events.

Diary cards. Patients recorded the presence or absence of daytime and night time reflux symptoms and the number of antacid tablets (Rennies, Nicholas: taken as required) used each day.

\section{ANALYSES}

Analyses of endoscopically assessed healing were carried out on an 'intention to treat' basis: in accordance with the protocol, one patient in each group in whom malignancy was detected was excluded. The target number of 240 patients gave a power of $80 \%$ to detect a true difference in healing rates of 20 percentage points at $p<0.05$ ( 2 tailed test). Cumulative healing rates at four and eight weeks were compared using MantelHaenszel test with stratification by entry endoscopy grade. In addition, a multivariate analysis using a logit model to assess the importance of various factors that were prognostic of healing was carried out.

Histology and clinical symptom data were analysed by Wilcoxon rank tests stratified by entry grade. Diary card data were analysed for the first two weeks of treatment by KolmogorovSmirnov tests. Correlations between endoscopic and histological grades at entry and of endoscopic grade and healing rate were carried out using Spearman's rank test.

Data are expressed as mean (SD) or with $95 \%$ confidence intervals $(\mathrm{CI})$. Therapeutic gain is the percentage healed in the omeprazole group minus the percentage healed in the cimetidine group.

\section{Results}

\section{PÁTIENTS AT ENTRY}

Of 272 patients, 138 were randomised to receive omeprazole and 134 cimetidine. The two groups were comparable in all respects at entry; details are given in Table I. Two patients (one in each

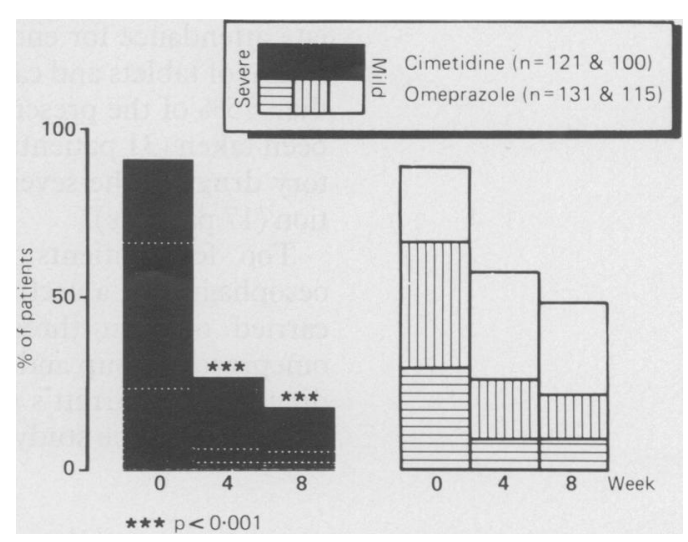

Figure 2: Resolution of heartburn in patients with reflux oesophagitis treated with omeprazole or cimetidine. The significance of differences between treatments is shown. 
group) were excluded from all analyses because of malignancy reported after randomisation.

\section{ENDOSCOPIC HEALING}

After four weeks, 77 patients in the omeprazole group and 34 in the cimetidine group had healed oesophagitis $(56 \% v 26 \%, \mathrm{p}<0.001$; therapeutic gain $31 \%, C I=19$ to $42 \%$ ). The corresponding cumulative figures at eight weeks were 97 (omeprazole) and 46 (cimetidine) patients $(71 \% v$ $35 \%, \mathrm{p}<0.001$; therapeutic gain $36 \%, \mathrm{CI}=24$ to $48 \%$ ). Details are shown in Figure 1, and healing rates analysed by endoscopic grade at entry in Table II. In the omeprazole group, healing rates were consistent after four weeks, irrespective of endoscopic grade at entry ( $r=-0 \cdot 65 ; \mathrm{ns})$, while in the cimetidine group, there was a significant inverse correlation between endoscopic grade at randomisation and healing rates $(\mathrm{r}=-0.99 ; \mathrm{p}=$ $0.001)$. The same pattern was seen after eight weeks (omeprazole, $\mathrm{r}=-0 \cdot 28$, ns; cimetidine, $\mathrm{r}=-0.98, \mathrm{p}<0.02)$. A further analysis was carried out to examine whether healing rates were related to the linear extent of the oesophagitis at endoscopy: the reported lengths affected were grouped as $\leqslant 4,5-9$, and $\geqslant 10 \mathrm{~cm}$. At four weeks, the healing rates in the omeprazole group were $59 \%, 56 \%$, and $45 \%$ and in the cimetidine group $29 \%, 23 \%$, and $17 \%$. At the end of the study, the figures were $75 \%, 70 \%$, and $54 \%$ (omeprazole) and 37\%, 36\%, and 17\% (cimetidine). Healing rates for both the omeprazole and cimetidine groups were significantly negatively correlated with the linear extent of the oesophagitis (all $\mathrm{p}<0.001$ ). The differences between healing rates in the omeprazole and cimetidine treated groups were statistically significant $(p \leqslant 0.001)$ except for the $\geqslant 10 \mathrm{~cm}$ groups in which the numbers of patients were too small for detection of any difference $(n=11$ and 12 respectively: Table I).

A second analysis, including only those patients known to have complied with the protocol, produced equivalent results. At four weeks 55 of $95(58 \%)$ patients on omeprazole and 23 of $84(27 \% ; p<0.001)$ patients on cimetidine had healed oesophagitis; after eight weeks, the figures were $78 \%$ and $44 \%(p<0.001)$. The therapeutic gain for omeprazole over cimetidine was $31 \%$ (CI 16 to $45 \%$ ) at four weeks and $34 \%$ (CI 20 to $48 \%$ ) at eight weeks. The main reasons for excluding patients from this analysis were late attendance for endoscopy (20 patients), the return of tablets and capsules indicating that less than $75 \%$ of the prescribed trial medication had been taken ( 31 patients), or the use of antisecretory drugs in the seven days before randomisation (17 patients).

Too few patients (Table I) had Barrett's oesophagus for a useful subgroup analysis to be carried out. In three of 10 patients in the omeprazole group and one of four in the cimetidine group, Barrett's oesophagus was recorded at the start of the study but not at the end. (73\% of randomised patients). At entry, 66 of

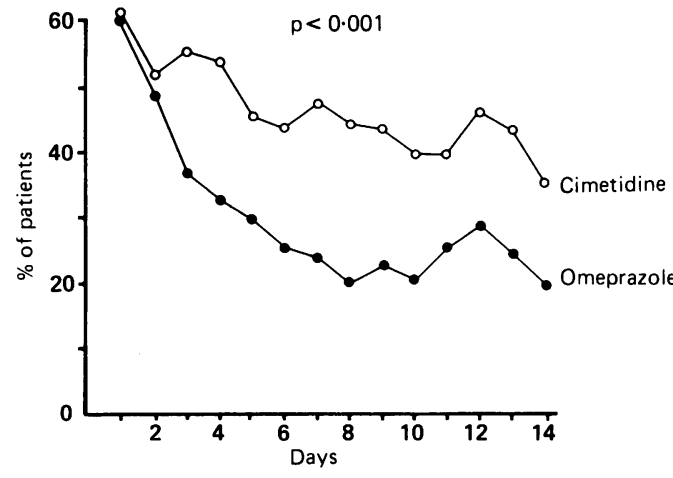

Figure 3: Proportion of patients with oesophagitis recording reflux symptoms by day during the first two weeks of treatmen with omeprazole $20 \mathrm{mg}$ om or cimetidine $400 \mathrm{mg}$ qds.

$104(63 \%)$ of these patients who received omeprazole had abnormal oesophageal histology (grade 1 and above). In the cimetidine group, the proportion was 56 of 94 (60\%). At entry, histological and endoscopic grades were significantly correlated $(r=0.26 ; p<0.001)$.

After treatment, $33 \%$ (22 of 66 ) of those receiving omeprazole continued to have abnormal histology compared with $52 \%$ (29 of $56)$ of those receiving cimetidine $(\mathrm{p}<0.001)$.

\section{HEALING: MULTIVARIATE ANALYSIS}

There was no evidence that age, smoking, alcohol consumption, or hiatus hernia predicted healing. Treatment (omeprazole favouring healing over cimetidine) was the only significant predictor of healing at both four and eight weeks $(p<0.001)$. Histology grade at entry predicted healing at four weeks $(p=0.037)$ and the endoscopy grade at entry predicted healing at eight weeks $(p=0.05)$.

\section{SYMPTOMS AT CLINIC VISITS}

All patients had symptoms at entry but after four weeks, $46 \%$ of those receiving omeprazole compared with $22 \%$ on cimetidine were asymptomatic $(p<0.001)$. By the end of the trial, these figures had risen to $66 \%$ and $41 \%$ respectively $(\mathrm{p}<0.001)$. The most common single symptom was heartburn, but there was no correlation between the severity of heartburn with either endoscopic grading $(r=0.04 ; p=0.49)$ or histological grading $(\mathrm{r}=0.02 ; \mathrm{p}=0.76)$ at entry. Heartburn resolved in a significantly greater proportion of patients receiving omeprazole than

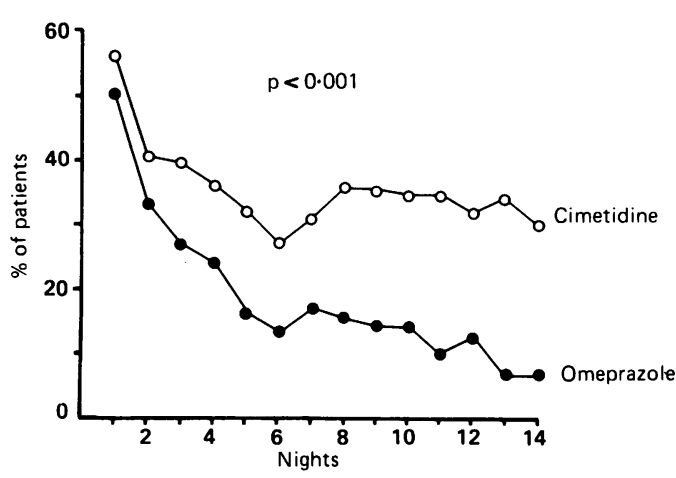

Figure 4: Night time symptoms of reflux during the first two weeks of the study. Presentation as in Figure 3. 
cimetidine by four and eight weeks $(\mathrm{p}<0.001$, (Fig 2)). Regurgitation was reported by $78 \%$ in the omeprazole group and $77 \%$ in the cimetidine group at entry but after four weeks' treatment, these figures had fallen to $30 \%$ and $48 \%$ respectively $(\mathrm{p}<0.01)$.

OVERALL OUTCOME: ALL CLINICAL ASSESSMENTS Endoscopy and symptoms. After four weeks, 50 (38\%) patients in the omeprazole group compared with $15(12 \%)$ in the cimetidine group $(\mathrm{p}<0.001)$ were both asymptomatic and had healed oesophagitis as assessed by endoscopy. A further $27(21 \%)$ in the omeprazole group and 19 $(16 \%)$ in the cimetidine group had healed oesophagitis but residual symptoms, and $10(8 \%)$ and $12(10 \%)$ patients respectively had relief of symptoms but still had oesophagitis. Forty four patients $(34 \%)$ on omeprazole and $75(62 \%)$ on cimetidine were neither healed nor had relief of symptoms.

Endoscopy, histology and symptoms. In a subgroup of 170 patients (93 in the omeprazole and 77 in the cimetidine group), all three types of assessment were complete at entry and at the end of the study. Of these, $42(45 \%)$ in the omeprazole group were healed endoscopically and histologically and were asymptomatic, a significantly greater proportion than in the cimetidine group $(17(22 \%)$ patients: $\mathrm{p}<0.01)$

\section{DIARY CARDS}

Diary card data were analysed for days two to 14 inclusive. Data were available for $84 \%$ (omeprazole group) and $81 \%$ (cimetidine group) of randomised patients. Results are shown in Figures 3, 4, 5, and 6. The differences between treatments were all significant $(p<0.001)$, with fewer omeprazole recipients having reflux symptoms by day or night, or taking antacids. Over the first two weeks, 121 patients taking omeprazole also took 1029 antacids (average 8.5 each) while 109 patients taking cimetidine also took 1642 antacids ( $p<0 \cdot 001$ : average $15 \cdot 1$ each). A significantly greater proportion of patients in the omeprazole group satisfied the strict criteria of having no daytime or night time reflux symptoms and taking no antacids: after two weeks, $74 \%$ of patients treated with omeprazole satisfied these criteria for symptom relief compared with $51 \%$ who received cimetidine.

\section{SAFETY}

Blood tests performed at the beginning and end of the trial did not show any trends for increased numbers of out of range values in either group.

Adverse events were reported during the study by $29(21 \%)$ patients receiving omeprazole and $24(18 \%)$ receiving cimetidine. Reporting did not imply a causal relation with the blinded trial medication. Nine $(7 \%)$ patients on omeprazole and $11(8 \%)$ on cimetidine were withdrawn because of adverse events. In all, 15 patients in the omeprazole group and 31 in the cimetidine group failed to complete the study.

Three adverse events were classified as serious. One patient (taking omeprazole) lost conscious-

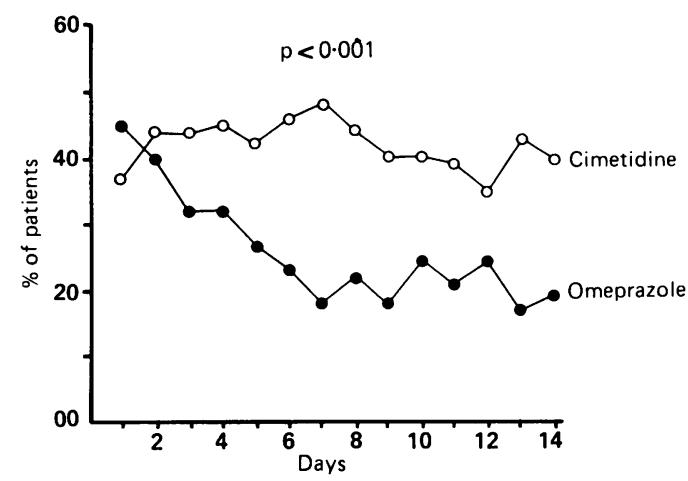

Figure 5: Proportion of patients taking antacids in addition to omeprazole or cimetidine for the treatment of reflux oesophagitis during the first two weeks of the study.

ness and had left-sided weakness after alcohol ingestion. The possible diagnoses were epilepsy with Todd's paralysis or transient cerebral ischaemic attack, thought to have been precipitated by the alcohol. A second patient (taking omeprazole) had a myocardial infarction, which was not judged to be related to the trial drug. The third patient had urticaria that was judged to be causally related to cimetidine.

\section{Discussion}

Omeprazole has been shown in other studies to be effective in relieving reflux oesophagitis. A greater proportion of patients on omeprazole have healed oesophagitis, when assessed endoscopically, and symptom relief within four and eight weeks than those receiving ranitidine. ${ }^{1-4}$ This study extends these observations to cimetidine given four times daily in a total dose of 1.6 g/day and to three types of assessment (symptomatic, histological, and endoscopic) in the same study. The advantage of omeprazole is not the result of poorer compliance with the four times daily regimen of cimetidine, for the therapeutic gain after four weeks was $30 \%$ in favour of omeprazole whether non-compliant patients and other protocol violators were included or excluded. Overall, twice as many recipients of omeprazole than of cimetidine had endoscopically healed oesophagitis at four and eight weeks. At entry, endoscopic and histological grades were correlated, but there was no correlation between symptoms and endoscopic or histological gradings, emphasising the importance of reliable measurements of each. ${ }^{5}$ In the

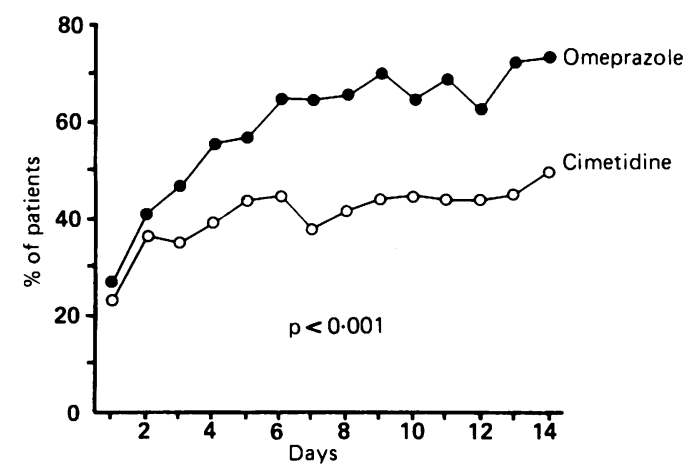

Figure 6: Proportion of patients free of reflux symptoms by day and by night and taking no antacids during the first two weeks of treatment with omeprazole or cimitidine. 
omeprazole group, healing, assessed endoscopically, occurred at roughly the same rate irrespective of severity at entry, whereas with cimetidine, the healing rates for patients with more than mild oesophagitis were low (Table II). Moreover, there were only small increases in the healing rates when the duration of treatment with cimetidine $1.6 \mathrm{~g} /$ day was increased from four to eight weeks: the therapeutic gain for omeprazole over cimetidine showed no sign of decreasing after eight weeks ( $31 \%$ at four weeks, $36 \%$ at eight weeks). Healing rates were correlated with the linear extent of the oesophagitis at entry - the healing rate for cimetidine in extensive oesophagitis $(\geqslant 10 \mathrm{~cm})$ was $17 \%$ at the end of the study and that for omeprazole was $54 \%$. A measurement of the linear extent of oesophagitis may be complementary to the more conventional endoscopic grading of severity in comparing drug effects. ${ }^{5}$

More rapid healing of the lesion, assessed endoscopically or histologically, is not the sole criterion for success of treatment. The speed of relief of symptoms is important for the patient and cannot be assessed solely at monthly clinic visits.

Diary cards have previously been shown to be a sensitive way of detecting differences in the speed of ulcer healing between omeprazole and $\mathrm{H}_{2}$ receptor antagonists. ${ }^{6-8}$ In this study, the differences were even more noticeable than in peptic ulcer disease: differences in symptom relief and antacid consumption became apparent after the first three days of treatment.

Both 24 hour oesophageal acid exposure and clinical dose finding ${ }^{10}$ studies indicate that $20 \mathrm{mg}$ once daily omeprazole is appropriate for the treatment of reflux oesophagitis. Where the oesophagitis remains unhealed after longterm, full dose $\mathrm{H}_{2}$. receptor antagonist treatment, $40 \mathrm{mg}$ omeprazole daily is more effective than high dose ranitidine. ${ }^{11}$ The present study shows that a dose of $20 \mathrm{mg} /$ day omeprazole is more effective by symptomatic, endoscopic, and histo- logical assessment than $1.6 \mathrm{~g} /$ day cimetidine in treating reflux oesophagitis, and that omeprazole heals oesophagitis irrespective of the severity of the disease.

Patients were recruited as follows: C M Bate (53), P W N Keelin (36), C O'Morain (24), S P Wilkinson (20), D N Foster (20) (36), C O'Morain (24), S P Wilkinson (20), D N Foster (20), R F Harvey (17), D G Thompson and V Mani (17), M Davis (17), I C Forgacs (12). The authors thank Drs Mani (Leigh) and Cairns (Preston) for their help, and also the following who contributed to this study: J H B Saunders, Bedford (6), M Al-Najar, Doncaste (5), A C B Wicks, Leicester (4), D N Clarke, Stirling (3), M Z K Rana, Bournemouth (1). We are particularly grateful to $D$ Geraint Williams, UHW Cardiff, who carried out all of the histological examinations. Alison Scrimgeour and Eva Hammarström analysed the study, and Carol Richardson prepared the manuscript.

1 Havelund T, Laursen LS, Skoubo-Kristensen E, et al. Omeprazole and ranitidine in treatment of reflux oesophagitis double-blind comparative trial. Br Med F 1988; 296: 89-92.

2 Van Trappen G, Rutgeerts L, Schurmans P, Coenegracht $\mathrm{J}-\mathrm{L}$. Omeprazole $(40 \mathrm{mg})$ is superior to ranitidine in shortterm treatment of ulcerative reflux oesophagitis. Dig Dis $\mathrm{Sc}$ 1988; 33: 523-9.

3 Klinkenberg-Knol EC, Jansen JMBJ, Festen HPM, Meuwissen SGM, Lamers CBHW. Double-blind multicentre comparison of omeprazole and ranitidine in the treatment of reflux oesophagitis. Lancet 1987; i: 549-1.

4 Sandmark S, Carlsson R, Fausa O, Lundell L. Omeprazole or ranitidine in the treatment of reflux oesophagitis. Scand f Gastroenterol 1988; 23: 625-32.

5 Funch-Jenson P, Kock K, Christensen LA, et al. Microscopic appearance of the esophageal mucosa in a consecutive series of patients submitted to upper endoscopy. Scand $\mathcal{F}$ Gastroonterol $1986 ; 21: 65-9$.

6 Crowe JP, Wilkinson SP, Bate CM, Willoughby CP, Peers EM, Richardson PDI. Symptom relief and duodenal ulcer healing with omeprazole or cimetidine. Aliment Pharmacol Therap 1989; 3: 83-91.

7 Bate CM, Wilkinson SP, Bradby GVH, et al. Randomised, double blind comparison of omeprazole and cimetidine in the treatment of symptomatic gastric ulcer. Gut 1989; 30 : 1323-8.

8 McFarland RJ, Bateson MC, Green JRB, et al. Omeprazole provides quicker symptom relief and duodenal ulcer healing than ranitidine. Gastroenterology 1990; 98: 278-83.

9 Robinson MG, Humphries TJ, McIntosh D, Allen ML Gagliola AJ, Broadstreet TE. Omeprazole dose response effect on 24 hour esophageal acid exposure in patients with effect on 24 hour esophageal acid exposure in patients with
symptomatic gastroesophageal reflux disease. Gastrosymptomatic gastroesoph
enterology 1989; 96: A420.

10 Hetzel DJ, Dent J, Reed WD, et al. Healing and relapse of severe peptic esophagitis after treatment with omeprazole. Gastroenterology 1988; 95: 903-12.

11 Lundell L, Westin IH, Sandmark S, et al. Omeprazole or high dose ranitidine in the treatment of patients with reflux oesophagitis not responding to standard doses of $\mathrm{H}_{2}$ receptor antagonists. Gastroenterology 1989; 96: A310. 